Pak. j. sci. ind. res. Ser. B: biol. sci. 2021 64B(2) 109-115

\title{
In vitro Antimicrobial Potential of Samples From the Leaves and Fruits of Medicinally Important Melia azedarach
}

\author{
Jehan Bakht ${ }^{a *}$, Ayesha Bukhari ${ }^{\mathrm{a}}$, Arshad Iqbal ${ }^{\mathrm{b}}$ and Mohammad Shafi ${ }^{\mathrm{c}}$ \\ ${ }^{a}$ IBGE, The University of Agriculture Peshawar, KPK, Pakistan \\ ${ }^{b}$ Department of Botany, Islamia College Peshawar, KPK, Pakistan \\ ${ }^{c}$ Department of Agronomy, The University of Agriculture Peshawar, KPK, Pakistan \\ (received October 3, 2018; revised May 11, 2019; accepted June 20, 2019)
}

\begin{abstract}
Different solvent extracted samples obtained from the leaves and fruits of Melia azedarach were investigated for their antibacterial and antifungal activities. All the extracts from both tissues sources showed varying degrees of antimicrobial activities. Ethyl acetate and n-butanol extracts of both tissues inhibited the growth of the tested micro-organisms at all concentrations. N-hexane extracted fractions of the leaves reduced the activity of Bacillus subtilis, Staphylococcus aureus, Escherichia coli and Pseudomonas aeruginosa at all concentrations, while no growth inhibition was recorded against Klebsiella pneumonia and Candida albicans. Crude methanolic extract from the leaves tissues showed activity against all the tested microbial species and highest susceptibility was noted against Bacillus subtilis. In case of leaves, the most susceptible bacteria were Bacillus subtilis (gram positive) and Klebsiella pneumonia (gram negative) was the most resistant one. In case of fruits extracts, the most susceptible bacteria were Klebsiella pneumonia (gram negative) and Escherichia coli (gram negative) was the most resistant one.
\end{abstract}

Keywords: antibacterial, antifungal, zone of inhibition, Melia azedarach

\section{Introduction}

The use of plants as herbal remedies has been documented by Chinese, Greeks, Romans, Egyptians, Syrians and Indians since 2800 B.C (Nessler et al., 1985). More than $50 \%$ of the deaths in tropical countries are resulted from various infectious diseases (WHO, 2005). Over the years, various pharmaceutical industries are constantly engaged to develop different antibiotics to cure these infectious diseases. However, in response to these synthetic drugs, microbes are also adopting different strategies and developing fast resistance (Hart and Karriuri, 1998). Therefore, these days the main goal of many pharmaceutical companies is to search plant based novel and cheap bioactive compounds with fewer side effects. About 25 to 45 percent of current prescriptions possess important bio-compounds obtained from plants as a major source of ingredients (Subramanian et al., 2009). Research shows that plants possess therapeutic effects due to different bio-active compounds produced by the plants (Khan and Khan, 2003). Hundreds of plants species have been investigated for their medicinal properties, however, most of them have not been scientifically studied (Mahesh and Satish, 2008). Different parts of a number of medicinally important plants are employed as extract for raw drugs *Author for correspondence; E-mail: jehanbakht@yahoo.co.uk having number of curative characteristics including antimicrobial activity (Bakht et al., 2018; Bilal et al., 2018; Ayaz et al., 2018; 2017; Wajid et al., 2017).

Melia azedarach, a member of family Meliaceae, is an important therapeutic plant present in Pakistan, Bangladesh, Southeast Asia, Australia, India and Indochina. Leaves are used to cure leprosy and as anthelmintic, diuretic, insecticide etc. Roots of the same plant are used as de-obstruent and resolvent. It is also used as antiseptic against ulcers and sores, rheumatism, skin diseases and malaria, analgesic, anti-cancerous, antiviral and antispasmodic (Biswas et al., 2002).

\section{Materials and Methods}

Plant material. The present study was conducted at IBGE, The University of Agriculture Peshawar Pakistan. Plant materials (leaves and fruits) of Melia azedarach were obtained from the research farms of the University of Agriculture Peshawar, KPK, Pakistan. The plant specimen was identified at the Department of Botany, University of Peshawar. After collection, the plant materials were washed thoroughly with distilled water, shade dried and grounded with electric grinder.

Crude extract preparation, fractionation and antimicrobial activity. Crude extract preparation, fractionation 
and antimicrobial activity (Table 1) was carried out as described by Bakht et al. (2018).

Statistical analysis. Data are presented as mean values of three replications. MSTATC computer software was used to carry out statistical analysis (Russel and Eisensmith, 1983). Least Significant Difference (LSD) test was employed to compare significant difference among means (Steel et al., 1997).

Table 1. Microbial strains used during the experiment

\begin{tabular}{|c|c|c|}
\hline $\begin{array}{l}\text { Microbial } \\
\text { species }\end{array}$ & $\begin{array}{l}\text { Gram } \\
\text { strain type }\end{array}$ & $\begin{array}{l}\text { Details of the } \\
\text { microbial strains used }\end{array}$ \\
\hline $\begin{array}{l}\text { Klebsiella } \\
\text { pneumonia }\end{array}$ & Negative & $\begin{array}{l}\text { Clinical isolate obtained from } \\
\text { Department of the Microbiology, } \\
\text { Quaid-I-Azam University } \\
\text { Islamabad Pakistan }\end{array}$ \\
\hline $\begin{array}{l}\text { Pseudomonas } \\
\text { aeruginosa }\end{array}$ & Negative & ATCC \# 9721 \\
\hline $\begin{array}{l}\text { Staphyloco- } \\
\text { ccus aureus }\end{array}$ & Positive & ATCC \# 6538 \\
\hline $\begin{array}{l}\text { Bacillus } \\
\text { subtilis }\end{array}$ & Positive & $\begin{array}{l}\text { Clinical isolate obtained from } \\
\text { the Department of Microbiology, } \\
\text { Quaid-I-Azam University } \\
\text { Islamabad Pakistan }\end{array}$ \\
\hline $\begin{array}{l}\text { Escherichia } \\
\text { coli }\end{array}$ & Negative & ATCC \# 25922 \\
\hline Candida & & ATCC \# 10231. Plant Pathology \\
\hline albicans & & $\begin{array}{l}\text { Department, The University } \\
\text { of Agriculture Peshawar } \\
\text { KPK Pakistan }\end{array}$ \\
\hline
\end{tabular}

\section{Results and Discussion}

Antimicrobial activity of samples from leaves. Bacillus subtilis showed highest susceptibility to crude methanolic extract (Fig. 1). Crude methanolic extract revealed highest inhibitory activity $(70 \% \mathrm{ZI})$ at concentration of $3 \mathrm{mg} /$ disc followed by $63 \%$ and $57 \%$ ZI at 2 and 1 $\mathrm{mg} /$ discs respectively when compared with control (DMSO). N-hexane extracted fractions showed 57\% inhibitory zone at $3 \mathrm{mg} / \mathrm{discs}$. Aqueous extracted sample was active at $3 \mathrm{mg} /$ discs, however, showed no activity against $B$. subtilis at lower concentrations of 1 and 2 $\mathrm{mg} /$ discs. N-butanol and ethyl acetate samples showed the lowest activity of $22 \% \mathrm{ZI}$ and $28 \% \mathrm{ZI}$ at $1 \mathrm{mg} / \mathrm{discs}$ concentrations respectively. Staphylococcus aureus showed highest susceptibility (67\% ZI) to n-butanol samples followed by ethyl acetate and $n$-hexane fractions (63\% and 51\% ZI respectively) at $3 \mathrm{mg} /$ discs. Aqueous extracted fractions showed no inhibitory activity, while crude methanolic extracts obtained from the leaves

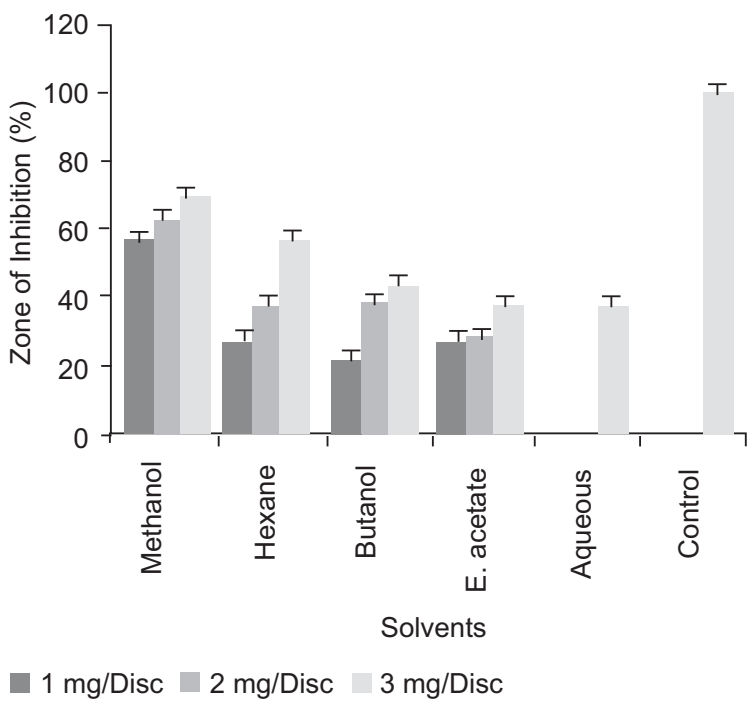

Fig. 1. Antibacterial activity of crude methanol, n-hexane, butanol, ethyl acetate and water extracted samples from the leaves of Melia azedarach against $B$. subtilis by disc diffusion assay $($ Control $=$ DMSO; Bar shows LSD at $\mathrm{P}<0.05)$.

showed minimum inhibitory activity of $28 \%$ at $1 \mathrm{mg} /$ discs (Fig. 2).

$\mathrm{N}$-hexane samples showed highest inhibitory zones of $48 \%$ and $47 \%$ against Escherichia coli at 3 and $2 \mathrm{mg} / \mathrm{disc}$ respectively. Crude methanol, ethyl acetate and n-butanol samples revealed 39\% each inhibitory activity at concentration $3 \mathrm{mg} / \mathrm{disc}$ against the same microbe. No inhibition was recorded in response to aqueous extracts, while lowest inhibitory zone was measured by n-butanol extracted samples (22\% ZI each) at 1 and $2 \mathrm{mg} /$ disc (Fig. 3). All the extracts showed inhibitory activity against Klebsiella pneumonia except n-hexane and aqueous samples. Klebsiella pneumonia showed maximum susceptibility to n-butanol samples ( $55 \% \mathrm{ZI})$ at $3 \mathrm{mg} /$ disc followed by $44 \%$ inhibition measured by n-butanol at $2 \mathrm{mg} /$ disc. Minimum inhibitory zone of $21 \%$ was revealed by crude methanolic extract at 1 $\mathrm{mg} /$ disc (Fig. 4). n-butanol and ethyl acetate samples reduced the growth of Pseudomonas aeruginosa by $52 \%$ ZI each at $3 \mathrm{mg} / \mathrm{disc}$ (Fig. 5). Crude methanolic extracts showed least inhibitory activity of $23 \%$ at $1 \mathrm{mg} /$ disc and no activity by aqueous extracted fractions at all the tested concentrations. Similarly, inhibitory activity of $41 \%$ was recorded by methanol extracted samples at $3 \mathrm{mg} /$ disc. Candida albicans was highly susceptible to ethyl acetate samples (54\% ZI each) at 2 and $3 \mathrm{mg} /$ disc followed by 


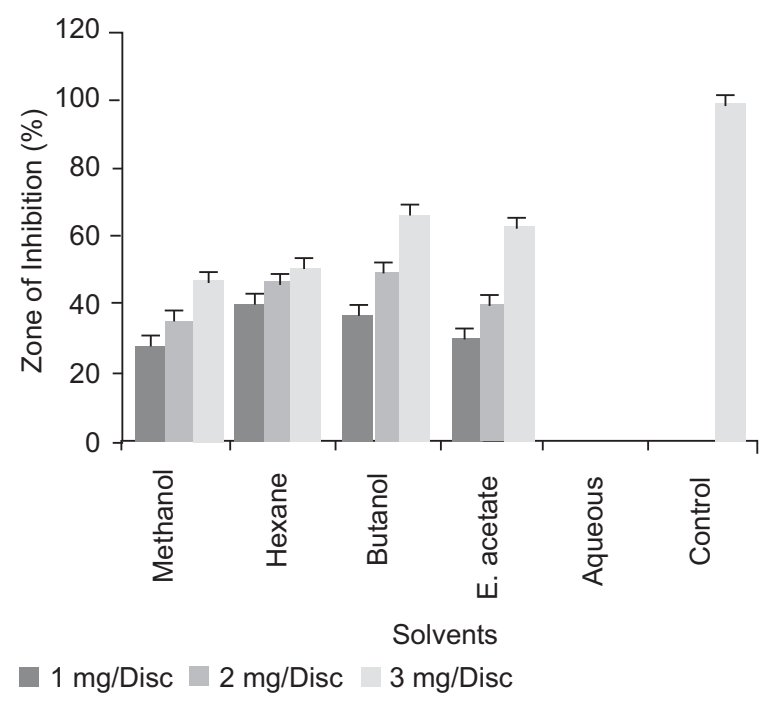

Fig. 2. Antibacterial activity of crude methanol, n-hexane, butanol, ethyl acetate and water extracted samples from the leaves of Melia azedarach against $S$. aureus by disc diffusion assay (Control = DMSO; Bar shows LSD at $\mathrm{P}<0.05)$.

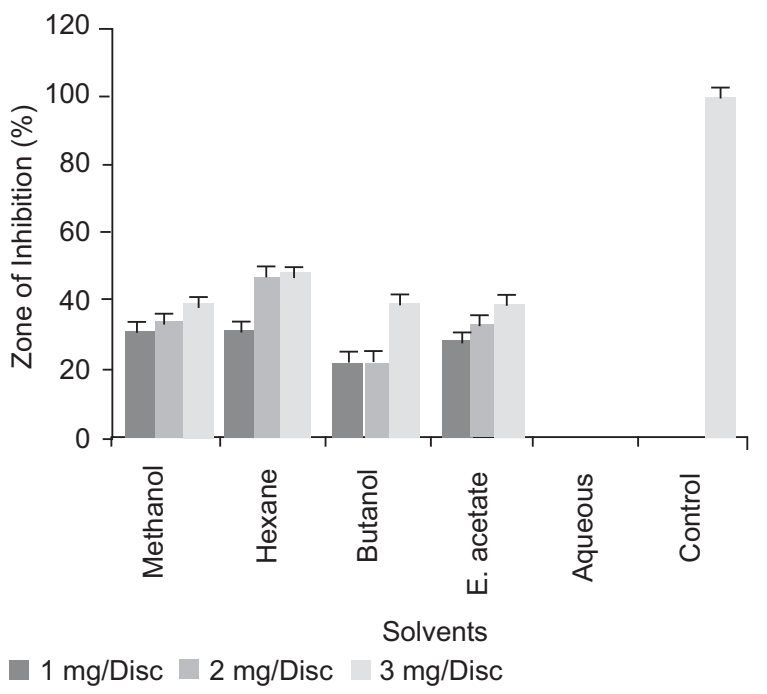

Fig. 3. Antibacterial activity of crude methanol, n-hexane, butanol, ethyl acetate and water extracted samples from the leaves of Melia azedarach against $E$. coli by disc diffusion assay $($ Control $=$ DMSO; Bar shows LSD at $\mathrm{P}<0.05)$.

n-butanol and crude methanolic extracts (47\% and 41 $\%$ ZI respectively) at the concentration. N-hexane and aqueous samples did not control the growth of C. albicans at all the tested concentrations (Fig. 6).

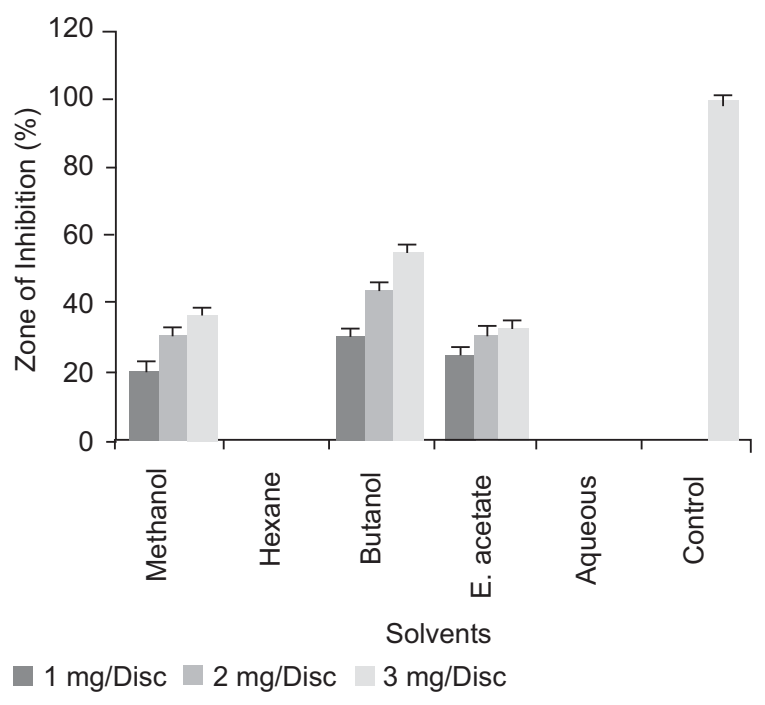

Fig. 4. Antibacterial activity of crude methanol, n-hexane, butanol, ethyl acetate and water extracted samples from the leaves of Melia azedarach against $K$. pneumoniae by disc diffusion assay (Control = DMSO; Bar shows LSD at $\mathrm{P}<0.05)$.

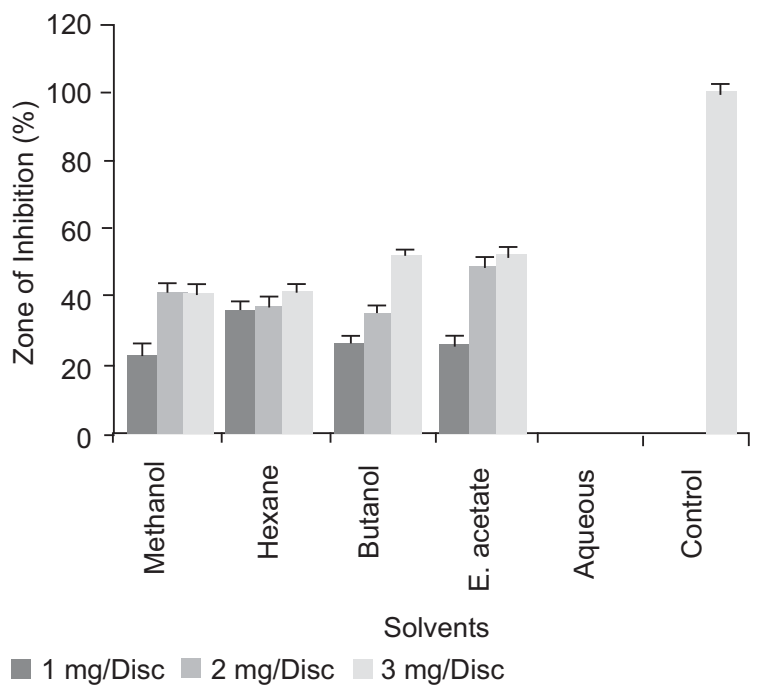

Fig. 5. Antibacterial activity of crude methanol, n-hexane, butanol, ethyl acetate and water extracted samples from the leaves of Melia azedarach against $P$. aeruginosa by disc diffusion assay (Control = DMSO; Bar shows LSD at $\mathrm{P}<0.05)$.

Antimicrobial activity of samples from the fruits. All the solvent extracted samples were effective against B. subtilis and inhibited its growth at all concentrations (Fig. 7). Ethyl acetate extracted fraction reduced the 
growth of B. subtilis by $63 \%$ at highest concentration. Crude methanolic extracts and ethyl acetate fractions inhibited the growth of the same microbe by $57 \%$ each at 3 and $2 \mathrm{mg} /$ disc. $n$-butanol reduced the growth of the

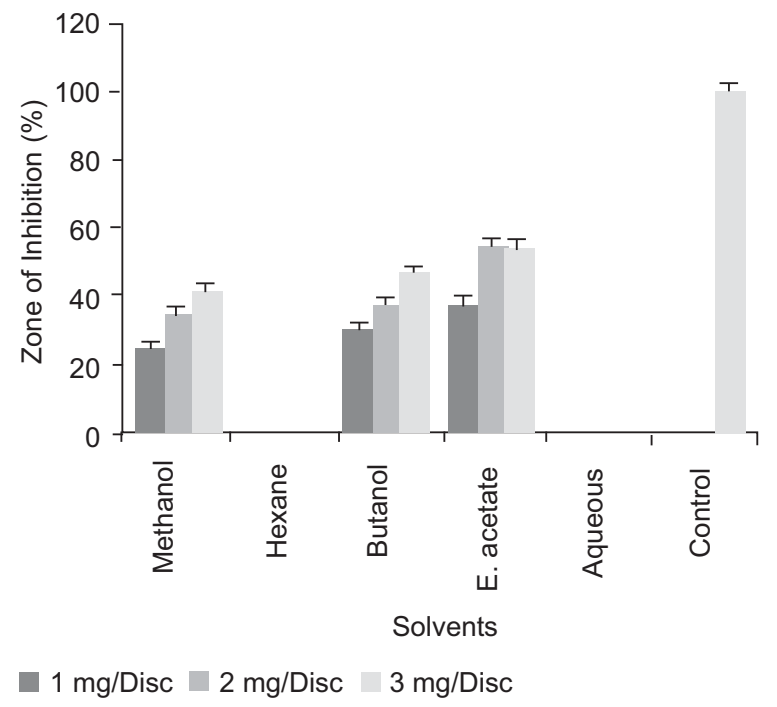

Fig. 6. Antibacterial activity of crude methanol, n-hexane, butanol, ethyl acetate and water extracted samples from the leaves of Melia azedarach against $C$. albicans by disc diffusion assay (Control = DMSO; Bar shows LSD at $\mathrm{P}<0.05)$.

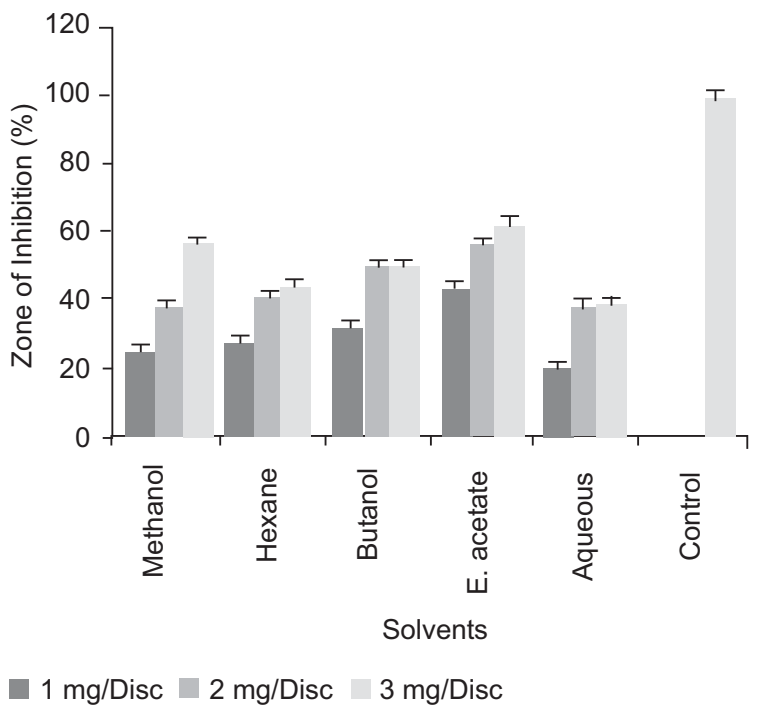

Fig. 7. Antibacterial activity of crude methanol, n-hexane, butanol, ethyl acetate and water extracted samples from the fruits of Melia azedarach against $B$. subtilis by disc diffusion assay (Control $=$ DMSO; Bar shows $\mathrm{LSD}$ at $\mathrm{P}<0.05)$. tested microbe by $50 \%$ each at 2 and $3 \mathrm{mg} / \mathrm{disc}$. The lowest inhibitory zone was measured for aqueous extracted samples $(20 \% \mathrm{ZI})$ at $1 \mathrm{mg} /$ disc. Ethyl acetate fraction was effective to control the growth of $S$. aureus by $60 \%$ and $57 \% \mathrm{ZI}$ at 3 and $2 \mathrm{mg} /$ disc respectively. n-butanol fractions reduced the growth of $S$. aureus by $54 \%$ at $3 \mathrm{mg} /$ disc. Lowest inhibitory zone was measured by $n$-hexane and aqueous samples $(23 \%$ ZI each) at concentration of $1 \mathrm{mg} / \mathrm{disc}$ and crude methanolic extract did not control the growth at lower concentrations of 1 and $2 \mathrm{mg} /$ disc (Fig. 8).

Ethyl acetate fractions exhibited the highest inhibitory activity against $E$. coli $(60 \% \mathrm{ZI})$ at $3 \mathrm{mg} /$ disc followed by $59 \%$ activity at $2 \mathrm{mg} /$ disc. $\mathrm{n}$-butanol samples showed $48 \%$ and $42 \%$ inhibitory activity at 3 and $2 \mathrm{mg} / \mathrm{disc}$ respectively. No activity was shown by aqueous samples. Crude methanolic extract though reduced the growth of the tested bacterium at 2 and $3 \mathrm{mg} / \mathrm{disc}$, however, did not affect the growth at lower concentration of 1 $\mathrm{mg} /$ disc. Minimum of $22 \% \mathrm{ZI}$ each was recorded for hexane crude methanolic and ethyl acetate samples at lower concenlation of concentration of $1 \mathrm{mg} /$ disc (Fig. 9). All the extracts obtained from the fruits inhibited the growth of $K$. pneumonia at different degrees. n-butanol extracted samples reduced the growth of the tested microbe by $80 \%$ and $64 \%$ at 3 and $2 \mathrm{mg} /$ disc respectively.

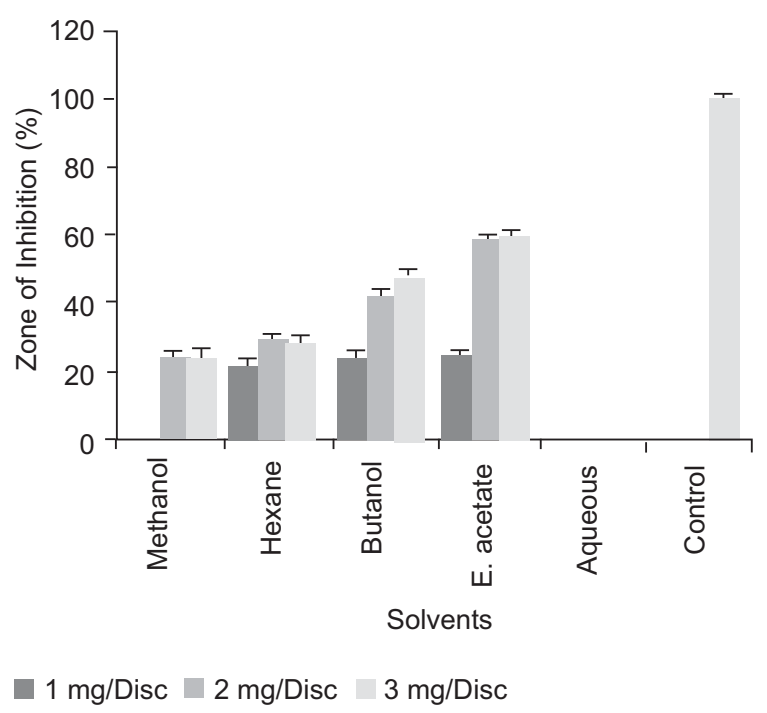

Fig. 8. Antibacterial activity of crude methanol, n-hexane, butanol, ethyl acetate and water extracted samples from the fruits of Melia azedarach against $S$. aureus by disc diffusion assay $($ Control $=$ DMSO; Bar shows LSD at $\mathrm{P}<0.05)$. 


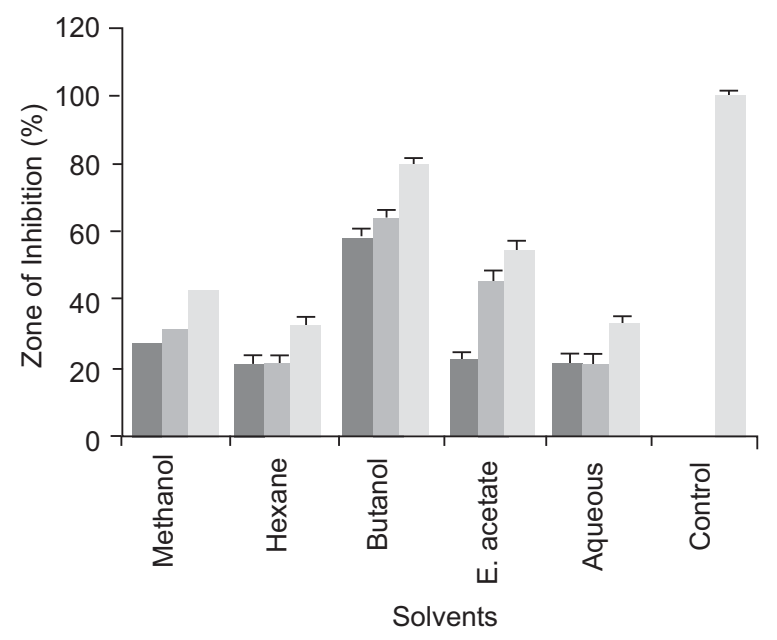

$1 \mathrm{mg} /$ Disc $2 \mathrm{mg} /$ Disc $\quad 3 \mathrm{mg} / \mathrm{Disc}$

Fig. 9. Antibacterial activity of crude methanol, n-hexane, butanol, ethyl acetate and water extracted samples from the fruits of Melia azedarach against $E$. coli by disc diffusion assay $($ Control $=$ DMSO; Bar shows LSD at $\mathrm{P}<0.05)$.

Ethyl acetate samples also showed good activity of 55\% ZI when applied in concentration of $3 \mathrm{mg} /$ disc. Minimum growth inhibition of $21 \%$ was measured for aqueous and n-hexane samples at 1 and $2 \mathrm{mg} /$ disc respectively (Fig. 10). P. aeruginosa was highly susceptible to nbutanol extracts $(58 \% \mathrm{ZI})$ at $3 \mathrm{mg} /$ disc. Ethyl acetate samples showed 52\% inhibitory zone each at higher concentration of 2 and $3 \mathrm{mg} /$ disc. n-hexane samples showed minimum inhibitory zone of $27 \%$ at $1 \mathrm{mg} /$ disc (Fig. 11) Ethyl acetate fractions showed maximum inhibitory activity of $88 \%$ at $3 \mathrm{mg} /$ disc followed by $60 \%$ inhibitory activity at lower concentrations. Fig. 12. The lowest inhibitory activity against the same fungal specie was measured for crude methanolic extracts $(23 \% \mathrm{ZI})$ at $1 \mathrm{mg} / \mathrm{disc}$.

The anti-bacterial activity of different solvent extracted samples from the leaves of Melia azedarach revealed that crude methanolic extracts effectively reduced the growth of B. subtilis at highest concentrations. Nhexane extracted fraction showed good activity at concentration of $3 \mathrm{mg} /$ discs Though aqueous extracted fractions was active at highest concentrations of 3 $\mathrm{mg}$ /discs, however, no activity was recorded against B. subtilis at lower concentrations. n-butanol and ethyl acetate samples showed the lowest activity at $1 \mathrm{mg} /$ discs. Khan et al. (2008) reported that ethyl acetate samples exhibited highest inhibitory activity followed by crude

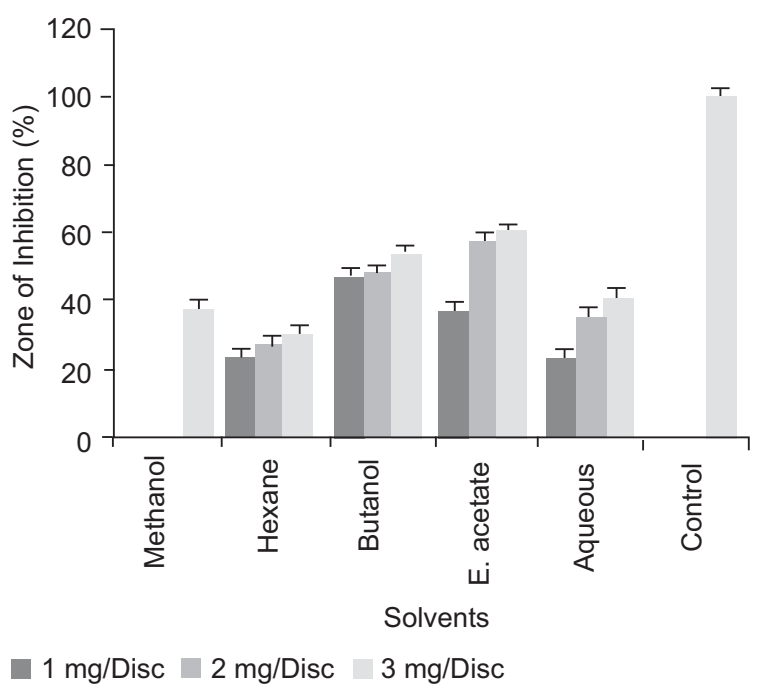

Fig. 10. Antibacterial activity of crude methanol, n-hexane, butanol, ethyl acetate and water extracted samples from the fruits of Melia azedarach against $K$. pneumoniae by disc diffusion assay $($ Control $=$ DMSO; Bar shows LSD at $\mathrm{P}<0.05)$.

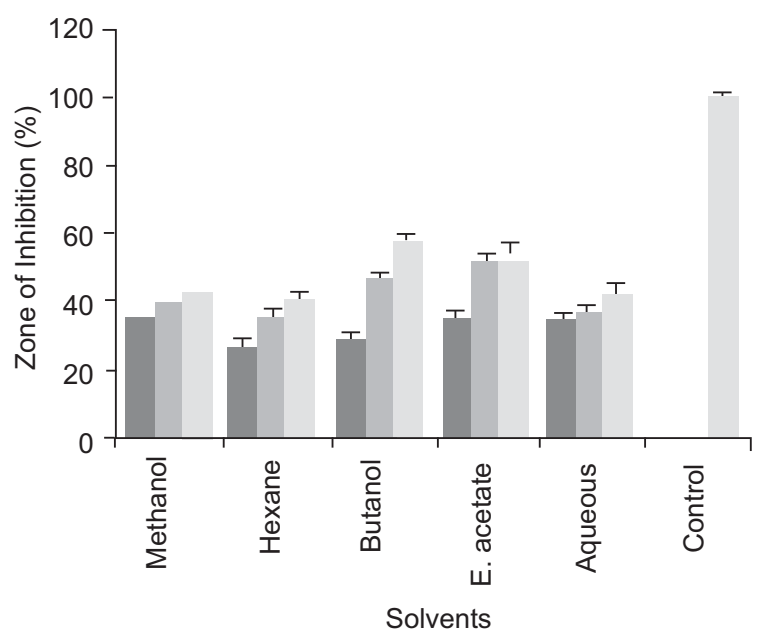

$1 \mathrm{mg} /$ Disc $\square 2 \mathrm{mg} / \mathrm{Disc} \square 3 \mathrm{mg} / \mathrm{Disc}$

Fig. 11. Antibacterial activity of crude methanol, n-hexane, butanol, ethyl acetate and water extracted samples from the fruits of Melia azedarach against $P$. aeruginosa by disc diffusion assay $($ Control $=$ DMSO; Bar shows LSD at $\mathrm{P}<0.05)$.

methanolic extract at different concentrations. S. aureus had more susceptibility to n-butanol extracted samples followed by ethyl acetate and n-hexane extracted fractions at highest concentrations. Aqueous extracted 


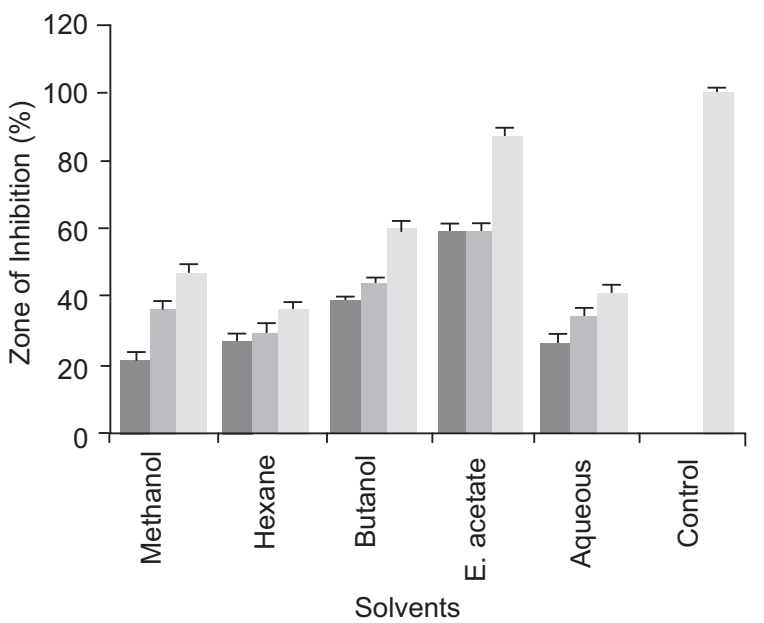

$1 \mathrm{mg} /$ Disc $\square 2 \mathrm{mg} /$ Disc $\square 3 \mathrm{mg} /$ Disc

Fig. 12. Antibacterial activity of crude methanol, n-hexane, butanol, ethyl acetate and water extracted samples from the fruits of Melia azedarach against $C$. albicans by disc diffusion assay $($ Control $=$ DMSO; Bar shows LSD at $\mathrm{P}<0.05$ ).

fractions measured no zone of inhibition and crude methanolic extracts showed minimum inhibitory activity at lowest concentration. Similar results are also reported by Ramya et al. (2009) and Khan et al. (2011). nhexane samples measured maximum zone of inhibition against $E$. coli at $3 \mathrm{mg} /$ disc. Ethyl acetate, methanol and and n-butanol samples also reduced the growth of the tested microbe at the highest concentrations. No inhibition was measured by aqueous extracts and minimum activity was recorded by n-butanol samples at lower concentrations. All samples showed inhibitory activity against $K$. pneumonia except n-hexane and aqueous extracted samples and measuring no activity at all the tested concentrations. K. pneumonia was more susceptible to n-butanol extracted samples at highest concentrations. These results agree with Khan et al. (2008) and Ramya et al. (2009). Analysis of the data indicated that $\mathrm{n}$-butanol and ethyl acetate extracted samples were very effective to control activity of $P$. aeruginosa. Crude methanolic extracts on the other hand, measured least inhibitory activity at lowest and no activity was recorded by aqueous extracted fractions at all the tested concentrations. C. albicans was highly susceptible to ethyl acetate samples at higher concentrations followed by $n$-butanol and crude methanolic extracts. $\mathrm{n}$-hexane and aqueous samples were ineffective against $C$. albicans at all the tested concentrations.

Antimicrobial activity of different solvent extracted samples from the fruits of Melia azedarach against $B$. subtilis indicated that increasing concentration of different extracts increased the activity against the tested microbe. All the solvent extracted samples were effective to reduce the growth of Bacillus subtilis at all the three concentrations. Ethyl acetate extracted fraction was more effective to control the growth of B. subtilis 3 $\mathrm{mg} /$ disc concentrations. Crude methanolic extracts nbutanol and, n-butanol extracted fractions also control the activity of the same microbe at 3 and $2 \mathrm{mg} / \mathrm{disc}$ concentrations. The lowest inhibitory zone was noted for aqueous extracted samples at concentration of 1 $\mathrm{mg} / \mathrm{disc}$ ) when compared with control. Ethyl acetate extracted fraction was more effective to reduce the activity of $S$. aureus at 3 and $2 \mathrm{mg} /$ disc concentrations. $\mathrm{N}$-butanol extracted fractions also reduced the growth of the $S$. aureus applied in concentration of $3 \mathrm{mg} / \mathrm{disc}$. Lowest inhibitory zone was noted for n-hexane and aqueous extracted samples at concentration of $1 \mathrm{mg} /$ disc. Crude methanolic extract was did not control the growth at lower concentrations of 1 and $2 \mathrm{mg} /$ disc concentration showing $0 \%$ ZI.

Ethyl acetate fractions from the fruits measured highest inhibitory activity at highest concentration against $E$. coli and n-butanol samples also reduced the activity of the same microbe at higher concentrations. No activity was shown by aqueous extracted samples. Crude methanolic extract though reduced the growth of the tested microbe at higher concentration however, did not show any activity at lowest concentration. n-butanol samples effectively controlled the growth of $K$. pneumonia compared with other fractions and controls n-butanol samples also reduced the growth of the tested microbe at higher concentrations. Ethyl acetate samples also showed good activity when applied in concentration of $3 \mathrm{mg} /$ disc. Minimum growth inhibition was measured for aqueous and n-hexane extracted samples at lower concentration. All the samples from the fruits caused maximum reduction in the growth of $P$. aeruginosa at all concentrations. $P$. aeruginosa was highly susceptible to n-butanol extracts at highest concentration. Ethyl acetate samples also showed good activity at higher concentration. Antimicrobial activity of n-hexane, ethylacetate, n-butanol, methanol and aqueous extracted samples from the fruits of Melia azedarach against $C$. albicans suggested that ethyl acetate extracted fractions 
showed maximum antimicrobial activity at highest concentration. The lowest inhibitory activity against the same fungus was noted for crude methanolic extracts at lowest concentration. These results agree with of the findings Khan et al. (2008).

\section{Conclusion}

The tested micro-organisms showed high sensitivity to n-butanol and ethyl acetate samples derived from the leaves and fruits. Against B. subtilis, crude methanol samples of leaves showed the highest activity as compared to other extracts. All the tested microbes were resistant to aqueous extract of leaves and moderate sensitivity was recorded in response to aqueous extract of the fruits. Ethyl acetate samples obtained from the fruits showed high antimicrobial activity. Samples from fruits showed maximum activity as compared to leaves. $K$. pneumonia and $C$. albicans were resistant to n-hexane and aqueous extracts of leaves and all the tested microbes showed moderate sensitivity to $n$-hexane extracts of fruits.

Conflict of Interest. The authors declare no conflict of interest.

\section{References}

Ayaz, A.S., Muhammad, A., Bakht, J. 2017. Pharmaceutical evaluation of different solvent extracted samples from Forsskaolea tenacissima. Indian Journal Pharmaceutical Science, 79: 257-266.

Ayaz, A.S., Muhammad, A., Bakht, J. 2018. Antinociceptive, antipyretic and antimicrobial activities of different solvent extracted samples from Chrozophora tinctoria. Indian Journal Pharmaceutical Science, 80: 533-540.

Bakht, J., Saman, F., Shafi, M. 2018. Impact of different extracts from leaves and fruits of Eucalyptus globulus on growth of different bacteria and fungi. Pakistan Journal of Pharmaceutical Science, 31: 1845-1852.

Bilal, M.K., Bakht, J., Wajid. K. 2018. Antibacterial potentials of the medicinally important plant Calamus aromaticus. Pakistan Journal of Botany, 50: 2355-2362.

Biswas, K., Chattopadhyay, I., Banerjee, R.K., Bandyopadhyay, U. 2002. Biological activities and medicinal properties of neem (Azadirachta indica). Current Science, 82: 1336-1345.

Hart, C.A., Kariuk, S. 1998. Antimicrobial resistance in developing countries. British Medical Journal, 317: $647-650$.

Khan, A.V., Khan, A.A. 2003. Herbal abortifacients used by folk people of some districts of Western Uttar Pradesh (India). Journal of Natural Remedies, 3: $41-44$.

Khan, A.V., Khan, A.A., Shukla, I. 2008. In vitro antibacterial potential of Melia azedarach crude leaf extracts against some human pathogenic bacterial strains. Ethnobotanical Leaflets, 12: 439-445.

Khan, A.V., Ahmed, Q.U., Mir, M.R. Shukla, I., Khan, A.A. 2011. Antibacterial efficacy of the seed extracts of Melia azedarach against some hospital isolated human pathogenic bacterial strains. Asian Pacific Journal of Tropical Biomedicine, 1: 452-455

Mahesh, B., Satish, S. 2008. Antimicrobial activity of some important medicinal plants against plant and human pathogens. World Journal of Agricultural Science, 4: 839-843.

Nessler, C.L., Allen, R.D., Galewsky, S. 1985. Identification and characterization of Latex-specific proteins in Opium poppy. Plant Physiology, 79: 499-504.

Ramya, S., Jepachanderamohan, P.J., Alaguchamy, N., Kalayanasundaram. M., Jayakumararaj, R. 2009. In Vitro antibacterial prospective of crude leaf extracts of Melia azedarach Linn. against selected bacterial strains. Ethnobotanical Leaflets, 13: 254-58.

Russel, D.F., Eisensmith, S.P. 1983. MSTAT-C. Crop Soil Science Department, Michigan State University USA.

Steel, R.G.D., Torrie, J.H., Dickey, D.A. 1997. Principles and Procedures of Statistics. A Biometrical Approach, $3^{\text {rd }}$ Edition. pp. 172-177. McGraw Hill Book Co. Inc. New York, USA.

Subramanian, R., Jepachanderamohan, P.J., Alaguchamy, N., Kalayanasundaram, M., Jayakumararaj, R. 2009. In vitro antibacterial prospective of crude leaf extracts of Melia azedarach Linn. against selected bacterial strains. Ethnobotanical Leaflets, 13: 254-258.

Wajid, A., Bakht, J., Bilal, M. 2017. In vitro antifungal, antioxidant and HPLC analysis of the extracts of Physalis philadelphica. Bangladesh Journal of Pharmacology, 12: 313-318.

W.H.O. 2005. Global Atlas of Traditional, Complementary and Alternative Medicine. World Health Organization, Geneva, page 28. 